\title{
Malignant Infantile Osteopetrosis - A Case Report
}

\author{
SOOFIA KHATOON ${ }^{1}$, NASIMAAKTER ${ }^{2}$, SM SHAHNAWAZ BIN TABIB ${ }^{3}$, ARM LUTHFUL KABIR ${ }^{4}$
}

\section{Introduction}

Osteopetrosis is a rare congenital, heterogeneous group of genetic disorders characterized by increased bone density due to impaired bone resorption by osteoclasts $^{1-5}$. It was first described by Albergs Schonberg in $1904^{6}$. It is one among the disorders causing osteosclerosis of tubular bone and/or hyperostosis of cortical bone ${ }^{2}$. Four types of human osteopetrosis have been reported ${ }^{2}$. That include severe malignant infantile osteopetrosis (MIOP) which is an autosomal recessive lethal form, adult benign autosomal dominant form, intermediate autosomal recessive osteopetrosis (ARO) and a distinct form of osteopetrosis due to carbonic anhydrase 11 deficiency associated with renal tubular acidosis, cerebral calcification and mental retardation ${ }^{7}$. Primary underlying defect in all types are abnormally dense bone formation and failure of resorption of calcified cartilage. This is due to failure of osteoclast to resorb bone. The increased bone fragility in osteopetrosis is due to failure of collagen fiber to connect osteons properly and also due to defective remodeling of woven bone into compact bone ${ }^{7}$.

Incidence of Osteopetrosis is 1 per 20,000-500,000 for dominant form and 1 per 200,000 for recessive form? ${ }^{7}$. Because of rarity of this type of malignant infantile form of osteopretrosis, we like to report this case.

\section{Case Report}

A 11 months old female child, only issue of consanguineous parents hailing from Narayanganj was admitted in ICMH in September 2004 with repeated attacks of low grade fever since 6th month of age and not growing well for same duration. The fever was not associated with chill and rigor but often associated with cough. She also had gradual distension of abdomen for last 2 months. She was born normally and had uneventful postnatal history. She has achieved neck control at 6th month of age and unable to stand at presentation. On examination, her weight was 5.5

1. Professor and Head of Paediatrics, Institute of Child \& Mother Health, Matuail, Dhaka

2. Registrar, Department of Paediatrics, Institute of Child \& Mother Health, Matuail, Dhaka

3. Department of Paediatrics \& Joint Director, Institute of Child \& Mother Health, Matuail, Dhaka

4. Professor of Paediatrics, Institute of Child \& Mother Health, Matuail, Dhaka

Correspondence: Prof. Soofia Khatoon kg (WAZ -4 SD: severe underweight and HWZ - 2 SD: moderate wasting), length was $67 \mathrm{~cm}$ (HAZ -7 SD: severe stunting), OFC- $42.5 \mathrm{~cm}$. There was prominent frontal bossing, depressed nasal bridge and wide open anterior fontanel. Patient was moderately pale and febrile (temperature- $100^{\circ} \mathrm{F}$ ). Cervical, axillary, epitrochlear lymph nodes were palpable, size less than $1 \mathrm{~cm}$, firm and non tender. Heart rate was 96/ min, respiratory rate was $36 / \mathrm{min}$. Liver was enlarged, $10 \mathrm{~cm}$ from right costal margin, firm, non tender, smooth surface and spleen was also enlarged, $12 \mathrm{~cm}$ along its long axis (Fig.-1). No neurological abnormality was found. Vision and hearing were normal. Skin and mucous membrane were also normal. Examination of other systems reveals no abnormality. Investigation revealed: $\mathrm{Hb}: 6.8 \mathrm{gm} / \mathrm{dll}, \mathrm{ESR}$ : $26 \mathrm{~mm}$ in 1st hr, TC : 30,000/cumm, N-21\%, L-51\%, M02\%, E-04\%, Band from: 03\%, Myelocyte: 03\%, Metamyelocyte: 02\%, Promyelocyte: 05\%, Blast cell$03 \%$. Blood film shows anisopoikilocytosis of red blood cells, mostly macrocytic. A fair number of tear drop cells and a small number of fragmented cells were present.

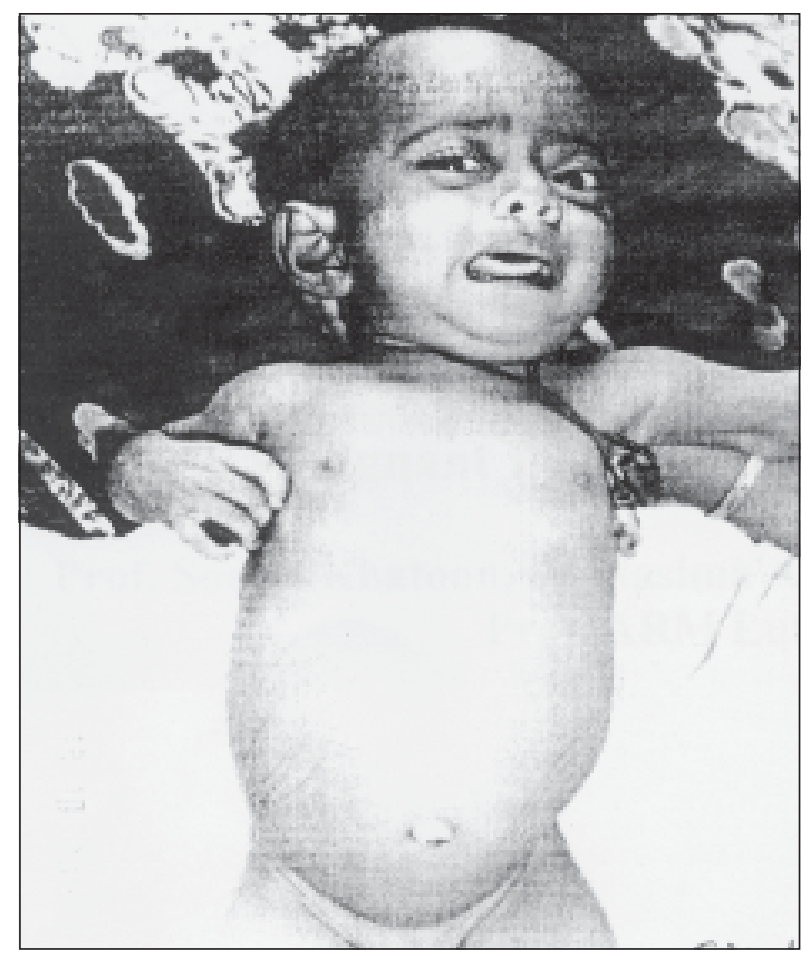

Fig.-1 : Showing Hepatosplenomegaly 
Nucleated red cells were present in a proportion of 25 per 100 leukocytes. Granulocytes show shift to the left down to the stage of myeloblast. However, immature cells including all the precursor cells accounts for about $20 \%$, basophils are not seen. Platelets are scanty. Comment: Leukoerythroblastic blood film.

S. calcium: $6.8 \mathrm{mg} / \mathrm{dL}$, Serum inorganic phosphate: 4.4mg/dL. Serum electrolytes showed sodium: 140 $\mathrm{mmol} / \mathrm{L}$, potassium: $4.07 \mathrm{mmol} / \mathrm{L}$, Chloride: $108 \mathrm{mmol}$ /L, Total $\mathrm{CO}_{2}: 21 \mathrm{mmol} / \mathrm{L}$, serum creatinine: $6 \mathrm{mg} / \mathrm{dl}$, serum alkaline phosphatase: $2600 \mathrm{U} / \mathrm{L}$. Blood group 'A' positive.

X-ray skull showed increased density in the bones of skull, more marked in periorbital bones, maxilla and mandible (Fig.-2). X-ray of lower limbs showed increased density in diaphysis of the long bones. There was wide band like translucency with coarse trabecular pattern in the metaphysis with loss of differentiation between cortex and medulla and having bone within bone (endobone) appearance. Increased density was also seen in epiphysis and in the bone of pelvis (Fig.-3).

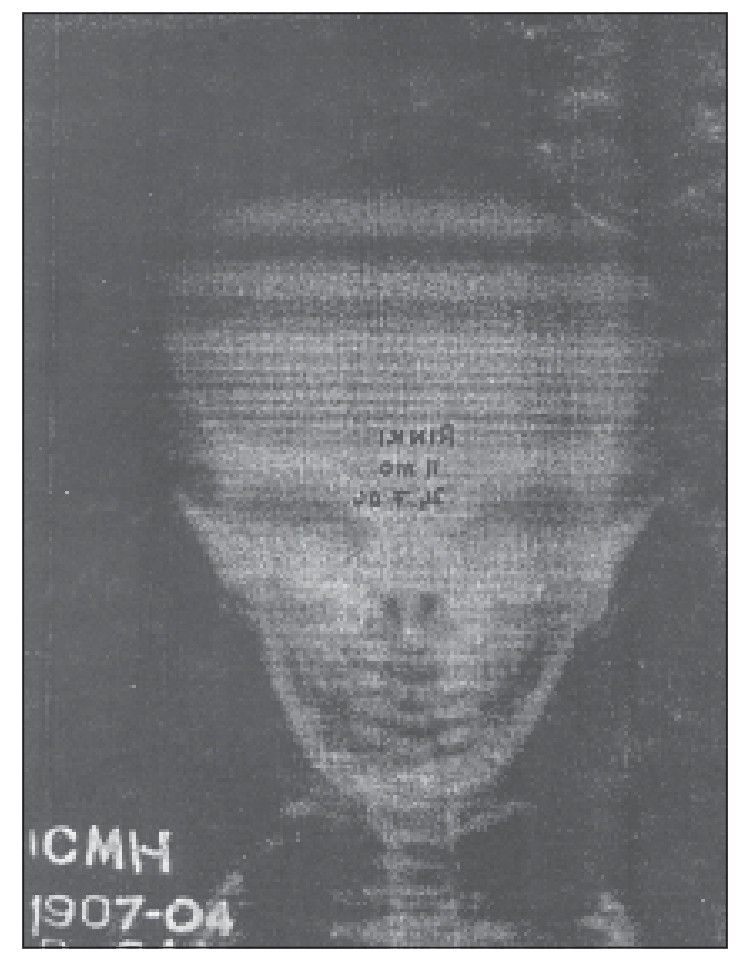

Fig.-2: X-ray skull showing thinkening of periorbital bones

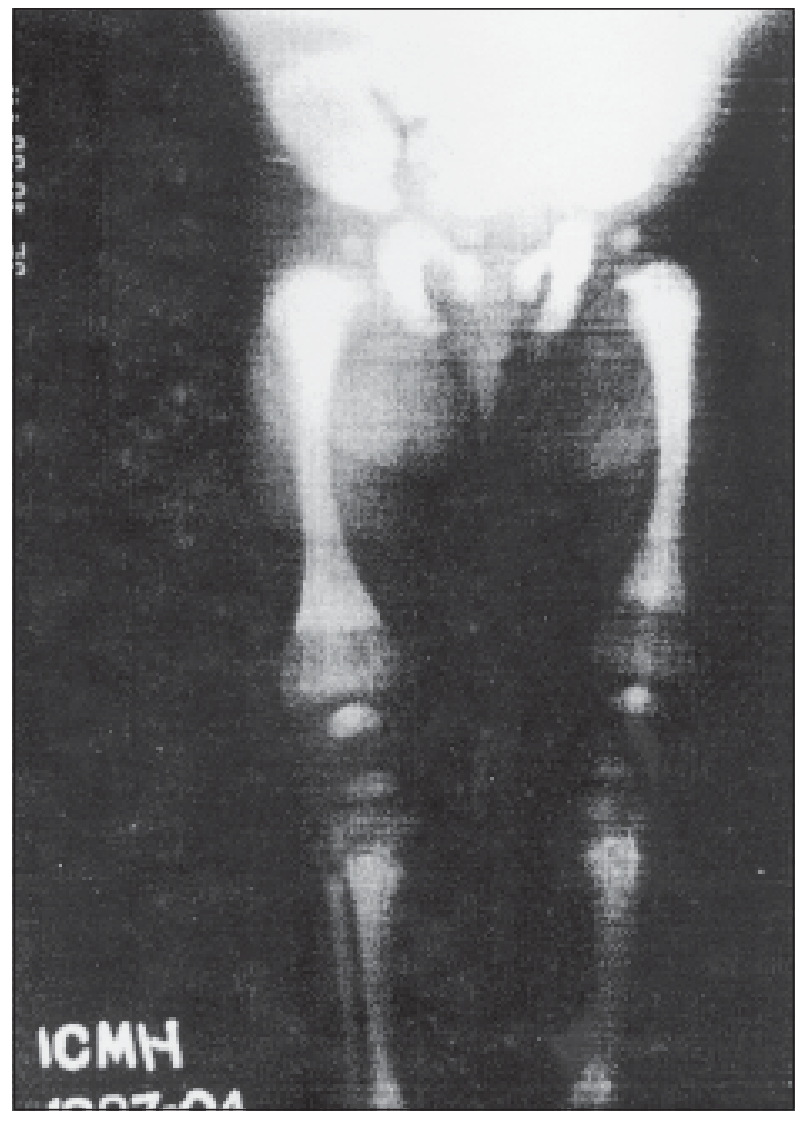

Fig.-3: $X$-ray lower limbs showing increased density of diaphysis of long bones

Bone marrow study showed a cellular marrow fragments. These were composed of haemopoietic cells trapped in fibrous elements. The cell traits showed depressed erythropoiesis with moderate dyserythropoiesis. Granulopoiesis showed left shifting. Megakaryocytes were not seen. A large number of osteoclasts was present. Features were consistent with Osteopetrosis.

She was diagnosed as a case of Malignant Infantile Osteopetrosis with failure to thrive. She was treated with antibiotic, blood transfusion, prednisolone, calcium and vitamin D (BON-D3) and feeding. She was discharged after 22 days with advice to attend follow up clinic in Paediatric outpatient department.

\section{Discussion}

Malignant infantile osteopetrosis (MIOP) is a rare genetically heterogeneous autosomal recessive disorder of bone metabolism, which if untreated has a fatal outcome ${ }^{8}$. The disease is caused by defect or mutation in gene ATP6i (vacuolar proton pump) or gene CIC-7 (chloride channel) ${ }^{3,4}$. Localization of gene 
causing autosomal dominant osteopetrosis type I was found in chromosome $11 q 12-13^{9}$. The pathogenic defects may be intrinsic to either the osteoclast monocyte lineage or the mesenchymal cells that constitute the microenvironment which supports osteoclast ontogeny and activation ${ }^{10}$. Because of heterogeneity of genetic defect, the disease presents with spectrum of clinical variants. MIOP is presented in early life. Our patient was symptomatic since $5^{\text {th }}$ month of age with failure to thrive. The growth failure was evidenced by severe stunting and underweight, moderate wasting. Defective resorption of osseous tissue tends to replace bone marrow which causes marrow failure. Patient may have recurrent infection, anaemia and hepatosplenomegaly which were present in our case. Recurrent infection is common due to defect in the immune systems and extramedullary erythropoiesis may result in hepatosplenomegaly?. Easy bruising and bleeding may be found due to thrombocytopenia and hypersplenism. Some times features of haemolysis are also found in $\mathrm{MIOP}^{7}$. But in our case no features of haemolysis and hypersplenism was found. Cells of promyeloid series may be found due to ineffective marrow function, which was found in this case.

The major clinical features derived from bony overgrowth of the marrow space and compression of optic and auditory nerve, which pass through the major foramina of the skull ${ }^{5}$. Although MIOP is a disease of bone, but most serious consequence is seen in nervous system ${ }^{3,4}$. Cranial nerve neuropathies occur due to failure of foramina in the skull to widen completely. Deafness, blindness, optic atrophy, proptosis, carpal tunnel syndrome may be the presenting features. Stroke is also reported in $\mathrm{MIOP}^{4}$. Patient may also present with nasal stuffiness due to mastoid and paranasal sinus malformation. But these manifestations were absent in our case. Gingival hyperplasia and nystagmus were reported in a 2 months old female child ${ }^{2}$. Dentition may be delayed ${ }^{1}$ but in our case teeth were present. In osteopetrosis bones are fragile and can cause fracture easily? Osteomyelitis of mandible is also common because of abnormality in blood supply ${ }^{7}$. Rickets which is termed osteopetrorickets is found as a complication of osteopetrosis with variable features ${ }^{5,11}$. This is due to failure of ostcoclasts to maintain normal calcium and phosphorus level in extracellular fluid ${ }^{11}$. Presence of rickets may worsen the symptoms of osteopetrosis which is associated with increased lethargy, irritability, poor feeding, growth retardation and pathological fracture. No features suggestive of rickets were found in our case. Parathyroid hormone is also found elevated in $\mathrm{MIOP}^{7,10}$. Parathyroid hormone was not assessed in our case. The diagnosis of osteoptrosis depends on the presence of positive radiographic features in bone ${ }^{2,12}$. Increased density is found in all types of bones which were found in our case. Bone density test and bone biopsy can confirm the diagnosis ${ }^{2}$. In our case bone marrow examination has confirmed the diagnosis.

Whatever therapies are given, the only potential curative therapy for MIOP at this time is a successful hemapoietic stem cell/ bone marrow transplant using either bone marrow or peripheral blood stem cells from a suitable matched sibling 2,5,6,9-11,13,14. An alternative option is hemapoietic stem cell/ bone marrow transplant from a partially matched family donor such as a parent or children ${ }^{15}$. Other management of patients with osteopetrosis requires a comprehensive approach to characteristic clinical problems including hematologic and metabolic abnormalities, fractures, deformity, bone pain, ostcomyelitis and neorologic sequelae ${ }^{10}$. Supportive treatment includes blood transfusion for anaemia, antibiotic for infection and orthopaedic treatment for fracture ${ }^{16}$. Optic nerve decompression, splenectomy has been performed in cases where indicated. Corticosteroid has been used in some cases with benefit for controlling anemia and thrombocytopenia and stimulating bone resorption but has been of no benefit in other cases ${ }^{7,10,17}$. Calcitriol has been used by some author leading to clinical improvement ${ }^{10,18}$. It is a bone resorbing agent which stimulates dormant osteoclasts and thus stimulates bone resorption. Erythropoetin can be used to correct anemia in osteopetrosis ${ }^{5}$. Treatment with gamma interferon improves white cell function that tremendously decreases the incidence of new infection ${ }^{7,10}$. Nutritional support and calcium supplementation are necessary to treat malnutrition and rickets. If untreated infantile osteopetrosis usually results in death by the first decade of life ${ }^{16}$.

\section{References}

1. de Vernejoul MC, Benichou O. Human osteoptrosis and other sclerosing disorders: recent genetic developments. Calcif Tissue 2001; 69: 1-6. 
2. Mohn A, Capanna R, Delli Pizzi C, Morgese G, Chiarelli F. Autosomal malignant ostcopertrosis: From diagnosis to therapy. Mincrva Paediatr 2004; 56: 115-18.

3. Frattini A, Pangrazio A, Susani L, Sobacchi C, Mirolo M, Abinun M et al. J Bone Miner Res 2003; 18: $1740-47$.

4. Steward CG. Neurological aspect of osteopetrosis. Neuropathol Appl Neurobio 2003; 29: 87-97.

5. Kulkarni ML. Osteopetrosis - Case reports. Indian Pediatr 2003; 40: 561-62.

6. Berkow R. The Mark Manual of Diagnosis and therapy. Osteopetrosis. $14^{\text {th }}$ edition, MSD, 1982 S, 1234-38.

7. http://www.emedicine.com/med/topic 1962.htmBhargavaA, Blank R. Osteopetrosis. 2002.

8. Sobacchi C, Frattini A, Orchard P, Porras O, Tezcan I, Andolina M, et al. The Mutational spectrum of human malignant autosomal recessive osteopetrosis. Hum Mol Genet 2001; 10: 1767-73.

9. Van Hut E, Gram J, Bollerslew J, Van WL, Mathysen D, Andersen PE. Localization of the gene causing autosomal dominant osteopetrosis type I to Chromosome 11 q 12-13. J Bone Miner Res 2002; 17: 1111-17.

10. Kocher MS, Kasser JR. Osteoptrosis. Am J Ortho 2003; 32: 222-28.
11. Kirubakaran C, Ranjini K, Scott JX, Basker M, Sridhar G. Osteopetroricketes. J Tro Paed 2004; 50: 185-65.

12. Stoker DJ. Osteopetrosis. Semin Musculoskeletal Radiol 2002; 6: 299-05.

13. Chen CJ, Chao TY, Chu DM, Janckila AJ, Cheng SN. Osteoblast and osteoclast activity in a malignant infantile Osteopetrosis patient following bone marrow transplantation. J Pediatr Haematol Oncol 2004; 26: 5-8.

14. Drissen GJ, Gerritsen EJ, Fischer A, Fasth A, Hop WC, Veys P, et al. Long term outcome of haematopoetic stem cell transplantation in autosomal recessive Osteopetrosis: an EMBT report. Bone marrow transplant 2003; 32: 657-63.

15. hltp: // www.stjude.omf/disease-Rare disease: Osteopetrosis ( malignant infantile form) summarise, Jan 2005.

16. Tabib SMSB, Halim MA, Islam MN. Osteopetrosis - A case report, Bang J Med Sci 1996; 391: 27-31.

17. Barr DGD, Geol KM. Disorder of bones and Collageu. In: Campbell AGM, McIntosh N, editors. Forfar and Arneil's Text book of Pediatrics. 4th ed. ELBS Churchill Livingstone UK; 199. P. 1656.

18. Key L, Carnes D, Cole S. Treatment of congenital osteopetrosis with high dose calcitriol. N Engl J Med 1984; 310: 409-15. 